Belousova, A. (2020). Functions of participants in the collaborative solution of thinking problems, International Journal of Cognitive Research in Science, Engineering and Education (IJCRSEE), (8), Special issue of Current Research and Trends in Cognitive Sciences 2020, 29-36.

Original scientific paper

UDK:

159.955 .075

Received: November, 01.2020.

Revised: November, 25.2020.

doi: 10.23947/2334-8496-2020-8-SI-29-36

Accepted: December, 11.2020.

\title{
Functions of Participants in the Collaborative Solution of Thinking Problems
}

\author{
Alla Belousova ${ }^{1 *}$ \\ 'Don State Technical University, Faculty of Psychology, Pedagogy and Defectology, Rostov-on-Don, Russian Federation, \\ e-mail: akbelousova@donstu.ru
}

\begin{abstract}
The article presents the results of an empirical study of the collaborative solution of thinking problems by groups of students. The study was conducted in the context of educational activities when students solve educational problems. The student group was divided into subgroups of four people; each subgroup was given a learning task. In accordance with the author's ideas, collaborative thinking is carried out through the implementation of the following functions: generation, selection, meaning transfer, implementation. These functions are distributed among participants in collaborative problem solving. The purpose of the study was to study the distribution of functions when students collaboratively solve thinking problems. To study the distribution of functions, the author used a questionnaire to determine the distribution of functions between students. The author has shown that in the process of collaborative problem solving, functions are distributed among the participants. It is revealed that in the processes of collaborative solution of thinking tasks, each group of students has a unique combination of functions, which the author defines as the group's thinking style.
\end{abstract}

Keywords: collaborative thinking, function, role, functional foundations, self-organization, regulation, thinking style, thinking, thinking tasks.

\section{Introduction}

Currently, in public practice, strategic guidelines have been identified, which include the development of collaboration, collaborative activities, and a culture of cooperation. The educational practice emphasizes the need to develop innovation competencies, the ability to think critically, the readiness to work in a team, creativity and entrepreneurship, the ability and willingness to take reasonable risks. This is evidenced, in particular, by the implementation and development of the Four Cs program (USA), the $21^{\text {st }}$ century skills Assessment and training program (ATC21S) (Griffin, Care, and McGaw, 2012; Griffin, Care, and Harding, 2015). Collaborative problem solving and collaborative thinking skills have been classified as $21^{\text {st }}$-century skills (Griffin, Care, and McGaw, 2012). In cognitive science, the study of the interaction paradigm in thinking and cognitive processes is actively developing (Belousova, 2013).

Thus, in social practice, in education, science, business, and management, attention is focused and programs are formed aimed at developing the skills and competencies of collaborative thinking, or collaborative thinking activity.

Currently, in cognitive psychology, many psychologists are conducting research on the problems of collaborative thinking in the paradigm of embodied cognition (Calvo and Gomila, 2008).

There are studies aimed at studying different types of problems in the context of collaborative solution: collaborative crossword solving as a form of collaborative thinking (Szary and Dale, 2013), mathematical and physical problems (Ahonen and Harding, 2018; Belousova, 2010; Harding et al., 2017), various characteristics of the problem (Griffin, Care, and Harding, 2015).

Problem Solving addresses cognitive and social aspects (Ahonen and Harding, 2018; Burch, Burch, and Batchelor, 2019; Hesse et al., 2015; Yuan, Xiao, and Liu, 2019) of collaborative problem solving.

Researchers are looking at different ways to use collaborative problem solving in educational practice (Ahonen and Harding, 2018; Care, Scoular, and Griffin, 2016; Griffin, 2017; Lioe, Fai, and Hedberg, 2006; Yuan, Xiao, and Liu, 2019), based on STEM learning (Chen, et al.,2019), when using online learning (Ahonen and Harding, 2018; Harding et al., 2017; Lipponen, 2002).

Hesse et al. (2015) identified five main areas in the design of collaborative problem solving. Definite cognitive skills were assigned to them: participation in the production and transmission of information;

${ }^{\overline{ }}$ Corresponding author: akbelousova@donstu.ru 
considering and taking into account the points of view of others; understanding the strengths and weaknesses of group members; regulating the process of problem solving; knowledge formation in the process of group interaction. In addition to these skills, social skills are also highlighted, which involve the development of participant management skills (Hesse et al., 2015).

The social side of collaborative problem solving has long been noticed by researchers of collaborative solutions, collaborative activities, and group interaction in various fields of psychology.

Various socio-psychological studies emphasize the fact of functional role distribution when solving various tasks by a group. R. Schindler also identified group roles: alpha, beta, gamma, and omega, which differ in their behavior and functions in the group (Gellert M, and Nowak C., 2000).

Analysis of interaction processes in group problem solving, undertaken by R. Bales (Rudestam, 1982), led to the identification of two functions that underlie people's acceptance of certain roles: the task-solving function and the support function. Each function is represented by a specific set of roles. The task solving function is represented by the roles: initiator, developer, coordinator, evaluator, and motivator. Roles associated with group support: mastermind, harmonizer, mediator, dispatcher, surveyor, wingman (Rudestam, 1982).

Further research in various fields of psychology led to a refinement of the set of roles performed by group members in solving various tasks. In Russian psychology, within the framework of the program-role approach, M. G. Yaroshevsky identifies the main set of group roles in solving scientific problems: an idea generator, a polymath, and a critic (Yaroshevsky, Yurevich, and Allakhverdyan, 2000). Similar data can be found in other theories (Gadzhiev, CH. M., 1983-generator of ideas, critic, activator, resonator of ideas, problem finders).

In management psychology, the classification of roles is widespread. Belbin, R. M. (1993), who believes that effectively working groups include eight group roles: coordinator (leader), idea generator, organizer of collective work, critic (controlling and evaluating link), implementer (practitioner), mover (person who supports performance), resource scout (contact specialist), finalizer - closer (inspector).

The list goes on and there are many empirical studies and concepts that present different sets of roles for participants in collaborative problem-solving processes.

\section{Concept of functional bases of collaborative thinking activity}

It seems to us that the described facts of the role distribution of the processes of collaborative problem solving can be interpreted as a manifestation of a general pattern concerning the self-organization of collaborative thinking activity. We assume (Belousova, 2002) that the roles previously identified by various researchers (Bales, R. F.,1950; Belbin, R. M., 1993; Gadzhiev, CH. M., 1983; Schindler, R., 1968; Yaroshevsky, Yurevich, and Allakhverdyan, 2000, etc.) are not certain types of activities fixed in them, but reflect the contribution made by each participant to the formation of psychological neoplasms that are formed in the course of collaborative problem solving. In our opinion, the phenomena of functional-role distribution of participants represent real functional relationships that arise in the system of collaborative problem solving or tasks.

Theoretically, we distinguish four functions (Belousova, 2002) that integrate the empirical experience of researchers: idea generation, selection, meaning transfer, and implementation.

One of the criteria underlying the distribution of functions is the participation of a person in the initiation and development of thinking, which is manifested in the reflection of contradictions, entering new information into the consciousness, image of the world of participants, in the processes of forming psychological neoplasms (goals, ideas, hypotheses of meanings, assessments, motives, needs), leading to dynamization and self-organization of the participants ' thinking activity.

We believe that the first stage in the formation of a goal in collaborative thinking activity is to reflect the contradiction and form assumptions and hypotheses based on it. This stage marks the beginning of the initiation of thinking activity. From the point of view of the dynamics of activity development, the initiation of thinking is one of the most mobile poles of thinking activity. In this regard, the pole associated with the greatest mobility of collaborative thinking activity is provided by the function, the content of which is the ability to primarily reflect contradictions in the subject content of the task and form some assumptions and hypotheses based on them. It is this function that stands out in the literature when it comes to "idea generators", the role of "alpha" (Gadzhiev, CH. M., 1983; Yaroshevsky, Yurevich, and Allakhverdyan, 2000; Schindler, R., 1968, etc.).

The next step in the self-organization of collaborative thinking activity aimed at achieving the goal and characterized by the development of the necessary neoplasms is associated with the selection function, i.e., with the selection and evaluation of assumptions and hypotheses. This function is assumed by a person in the role of a critic: he considers the proposed assumptions, hypotheses, as if sifting through 
information, selecting the necessary and cutting off the irrelevant. These operations assume that the critic has formed ideas about the main contradictions of the problem, i.e. a structured psychological situation (Tikhomirov, 2002).

The information selected and sorted out by the critic is the concrete basis that is transformed into a goal in the next steps. However, the stated assumptions, hypotheses, do not yet imply their mandatory acceptance by the other members of the group, or by the partner. The final verbalization and definition of the goal are necessary, bringing it to the partner. Therefore, in collaborative thinking activity, the following function is necessarily distinguished: transmitting hypotheses and assumptions that arise from the generator and selected by the critic to the rest of the group members, as well as organizing activities for their implementation. This function plays a very important role in goal formation in collaborative thinking activity. If we consider the main content of this function, its essence is the processes of the content transfer, that is, transferring of meanings of the purpose, meanings, psychological neoplasms, meanings of the information to other participants.

In individual thinking activity, meaning formation and meaning transfer are merged and form an integral part of goal formation (Tikhomirov, 2002). In collaborative thinking activity, while preserving for each participant the general laws of individual thinking activity, meaning formation as the formation of common meanings of objects looks somewhat different. In collaborative thinking activity, meaning formation, as we have shown (Belousova, 2002), is realized through the processes of meaning transfer. Thus, meaning transfer in collaborative thinking activity performs two tasks: meaning formation (formation of general meanings) and translation, or transfer of meanings, meaning transfer itself. In a group, to form a common goal, it is necessary for all participants to accept it, and for this purpose, the meaning of assumptions, hypotheses, is brought to everyone. This role is assumed by the coordinator, performing the functions of meaning transmission. Reflecting the meaning, value assumptions, hypotheses, coordinator of the dialogue conveys their meaning to other participants, thereby forming shared meanings, structured common understanding of the situation and make a general psychological situation. As a result of these processes, participants accept hypotheses, assumptions, goals, and then hypotheses, assumptions, and goals become common, since their meaning is included in the overall psychological situation.

In the general system of collaborative thinking activity, the function of meaning transfer is rather close to ensuring stability: goal formation, which begins with a generator that offers an idea, continued by a critic who selects the most relevant ideas, ends with a coordinator who brings the idea to everyone and turns it into a system - forming factor-a goal. Thus, the level of mobility of collaborative thinking activity from function to function decreases, but at the same time the level of stability increases. Therefore, the more mobile and less stable the generation, the less mobile and more stable the selection function, i.e., the selection and evaluation of ideas, the more the function of meaning transfer tends to the stability pole. The function of meaning transfer carries mobility (you have to follow the movement of the generator and the critic), but it is more stable, since in order to organize and implement activities, you need to stop, fix your choice on a certain idea.

So, it is possible to predict that the function of ensuring stability in collaborative thinking activity will be assumed by the one of the participants who implements its norms, namely, the one who more or less successfully performs this function. What does the sustainability function mean? In individual activities, this role is played by the set (Uznadze, 2001). The stability of collaborative thinking activity is mainly provided by the implementation function, which is one of the least mobile among other functions. Representing a pole of stability, it involves the implementation of the formed goals.

But this function is necessary, because it is the final link in the functional support of self-organization of collaborative thinking activity, one of the most important. Without it, the activity is unproductive, devoid of its result, since it involves the implementation of the formed actual neoplasms. In the self-organization of the system of collaborative thought activity, this function is more responsible for maintaining stability. Thus, self-organization of collaborative thought activity presupposes the presence of participants who take on the goal-realizing function and ensure the greatest stability of the system, its goal-preservation.

Thus, in functional terms, self-organization of collaborative thinking activity as goal achievement, or goal formation is represented as follows. The generation of suppositions, hypotheses, and goals begins, creating a substantive basis from which some hypotheses, goals, and assumptions are evaluated positively and selected, while others are evaluated negatively. Negative ratings are perceived by all participants, including the generator, which continues to generate other assumptions, hypotheses, and goals based on them. Selected by the critic of the assumptions hypothesis or targets are reflected by the coordinator, their meaning is communicated by the coordinator to other members of the group, and formed a common sense of purpose (hypothesis, assumptions), giving rise to the common goal of the participants, which determines their collaborative action. The coordinator's activity creates a certain emotional background, 
which completes the integration of participants and the goal is realized.

At the same time, we emphasize that the distribution of these functions among the participants is free: each person performs the function that corresponds to him, and in relation to the intellectual and personal characteristics of the other partners in the solution. The fact of functional distribution is not rigidly fixed between the participants and at various stages of the decision, that is, movement and thinking, there is a redistribution of functions.

Summarizing, we can conclude that the selected functions are components of collaborative thinking activity and the formation of psychological neoplasms to solve problems and tasks. Moreover, and we want to emphasize this, it is not collaborative thinking activity that leads to the division of functions, but the self-organization of a system of collaborative thinking activity, i.e. a group of people who think together, in its functional plan is possible only when they are distributed. Thus, stability and mobility, selectivity and orientation, dynamics of emerging psychological neoplasms and self-organization of collaborative thinking activity are provided by the functional distribution of participants.

In our opinion, it is very important to understand the relationship between functions and roles, or between functions and participants who implement these roles. The functions of generation, selection, meaning transfer and implementation are among the permanent components, the interaction of which leads to self-organization and development of collaborative thinking activity, to the ability to form and develop common neoplasms for participants, to solve problems and tasks together. But this constancy of the functions that structure collaborative thought activity does not mean that they are permanently assigned to certain participants. Here, a different process is observed: the roles of the generator, critic, coordinator, and implementer are dynamic, they change, although they are limited by the development of personal qualities of each participant in a collaborative decision, its capabilities, goals, needs, and their relationship with partners.

So, the analysis of the functional support of collaborative thinking activity allows us to say that in the system of collaborative thinking activity there is a complex inter-individual formation of a functional nature, which performs the functions of self-organization. This mechanism of collaborative thinking activity is objectified in the form of distribution of functions between participants in collaborative problem solving.

It was interesting for us to see how functional support occurs when solving problems together in real life, in the course of students 'educational activities at the University. The process of solving educational problems is one of the spheres of students 'life reality, the main activity through which their professional development and formation takes place (Craig and Baucum, 2001).

\section{Materials and Methods}

To study and analyze the self-organization of collaborative thinking activity in the processes of collaborative solving professional problems, we conducted an experimental study in natural conditions. The study involved 180 students from various universities in Rostov-on-Don. The course of the study was as follows: students in the organization of classes in psychology were offered to solve the problem. Classes were conducted using the "small group" method, which involves dividing the student group into subgroups of four people. Each subgroup was solving a separate the task. At the end of the lesson, students of each subgroup were asked questions aimed at studying the functional distribution in groups (Belousova, 2002). The questions were formulated in such a way that each participant could evaluate the participation of partners in the performance of the function. Each function had two questions.

Based on the responses of group members, the frequency characteristics of each participant's performance of certain functions were calculated. We used data obtained during 5 classes. The data obtained were processed based on two analysis plans: first, the analysis of the ratio of functions between participants in relation to collaborative thinking activity; second, the analysis of the ratio of functions characteristic of individual thinking activity. Primary quantitative data processing was based on taking into account the accumulated frequency of functions performed by each member of the subgroups. 


\section{Results and Discussions}

The analysis made it possible to see that, indeed, there is selectivity in taking on certain functions by participants.

Table 1

Average values of functions in groups in the course of solving problems

\begin{tabular}{lccc}
\hline \multicolumn{1}{c}{ Functions } & Average values & Standard deviation & Standard error of the mean \\
\hline Generation & 23,00 & 19,66 & 3,42 \\
Selections & 20,52 & 19,36 & 3,37 \\
Meaning transfers & 18,88 & 18,57 & 3,23 \\
Implementations & 22,94 & 21,46 & 3,74 \\
\hline
\end{tabular}

Analysis of the average values for each of the functions shows that the highest and almost identical average values are observed in the generation function (23.00) and the implementation function (22.94), followed by the selection function (20.52) and meaning transfer (18.88) (Table 1).

In the experimental groups, the functions of implementation (32.96 \%) and generation $(29.55 \%)$ are more pronounced, which are most often assumed by participants. In equal proportions, the roles of critic and coordinator related to the implementation of the functions of selection and meaning transfer are distinguished in the groups (12.50\%). And a fairly high percentage (12.50) falls on the share of students who do not have a pronounced dominance of certain functions.

The use of the Student's T-test for paired samples showed that there are significant differences between the generation and selection functions ( $\mathrm{t}=2.466$ with a confidence level of 0.019 ), between the generation and meaning transfer functions ( $\mathrm{t}=3.995$ with a confidence level of 0.000$)$, and between the meaning transfer and implementation functions ( $t=2.662$ with a confidence level of 0.012$)$. The differences between the other functions were insignificant.

The obtained data allowed us to fix different functional relationships in the studied subgroups. If we consider the functional ratio as one of the indicators of dynamic processes of self-organization of collaborative thinking activity, we can say that the ratio of functions in a group in the course of collaborative problem solving creates a certain profile, which is manifested in the dynamics and direction of thinking.

In general, we can conclude that systems of collaborative thinking activity are self-organized in the process of solving problems due to the distribution of functions between participants. The distribution of functions between participants resembles a mechanism whose purpose is to regulate thinking activity. However, in collaborative thinking activity, this mechanism is associated with the dynamics of functions, the ratio of which differs in each group.

We can interpret the results obtained as evidence of an individually peculiar outline of the functions performed by a person when solving problems in a group, which brings us back To L. S. Vygotsky's ideas about the functional nature of the psyche $(1983 ; 1986)$.

Since we have identified four functions through which the self-organization of collaborative thinking activity is carried out, the dominance of one of them in the structure of functions performed by the group, and created the basis for highlighting the originality of collaborative thinking of this group. We interpret this orientation of the originality of the group's collaborative thinking as a stylistic originality of collaborative thinking. Thus, the studied subgroups clearly differ in the level and ratio of functional support for collaborative problem solving, which is defined by us as the thinking style of each group.

We conducted a simple quantitative analysis aimed at calculating the percentage of the orientation of thinking in different subgroups. The results were distributed as follows in descending order: practical - (31\%), initiative - (17\%), critical - $(15 \%)$, managerial - $(10 \%)$. At the same time, we can also observe groups that are dominated by two $(21 \%)$ or three $(1 \%)$ or even four $(5 \%)$ functions, which indicates an unexpressed style of thinking in these groups. Thus, we can see that there are pronounced differences in the orientation of the group solution, and these differences are related to the dominant type of functions in the functional support of the solution. In accordance with the kind of function, dominant among the rest, the following styles of thinking groups: a proactive style - the dominant function of generation; critical style is dominated by a function selection; management style - meaning transfer function dominates; practical style - the function implementation dominates.

The results obtained are consistent with the research of Dautov, D. F. (2009), aimed at studying the effectiveness of collaborative thinking activity in student groups that solve various types of problems. The research was based on theoretical ideas (Belousova, 2002) about the functions: generation, selection, 
meaning transfer, implementation, providing collaborative thinking activity. Dautov found that when problem solving is organized, when roles are distributed among students, there is a higher efficiency of collaborative thinking activity in student groups (Dautov, 2009). His research also highlighted certain personal characteristics of participants that affect the distribution of functions in collaborative thinking. Our research echoes the results of T. Pavlova (Pavlova, 2015), who studied the ontogenetic aspect of the problem under study. In the study of collaborative problem solving by preschool children, vol. Pavlova found that the distribution of functions between preschoolers is associated with the characteristics of the personality type.

We believe that the results obtained indicate, first, a general interindividual psychological mechanism distributed among group participants and existing in the form of functions assumed by participants, as it was noted by many researchers (Bales, R. F.,1950; Belbin, R. M., 1993; Gellert M, and Nowak C., 2000; Gadzhiev, CH. M., 1983; Schindler, R, 1968; Rudestam, K. E., 1982; Yaroshevsky, Yurevich, and Allakhverdyan, 2000); secondly, that the very situation of cooperative interaction of various people with unique personal qualities leads to the dynamics of functions in the collaborative solution of thinking problems, generating a stylistic originality of collaborative thinking.

The results also allow us to speak about the presence of a kind of "contribution" of each participant to collaborative thinking activity. This "contribution" is expressed in the assumption by each participant of the primary performance of functions. We believe it is possible to interpret this fact, returning to the ideas of Vygotsky L. S. (2005), as exteriorization and resocialization of functions previously formed by man in ontogenesis. The performance of certain functions by each person, their correlation with the functions performed by other participants, and provides a unique vector and direction of collaborative thinking activity of each group, its stylistic originality.

\section{Conclusions}

1. Thus, the analysis of the processes of collaborative thinking activity processes in groups of students allows us to say that in the course of its implementation, a complex inter-individual education arises, which performs the functions of self-organization. This mechanism of collaborative thinking activity is objectified in the form of distribution of functions between group members. The functions that ensure the self-organization of the system of collaborative thinking activity include the following: generation, selection, meaning transfer, implementation.

2. The Presented results allow us to see a different ratio of functions in each group, which gives a peculiar character to the collaborative solution of problems by each group. This correlation of functions in the processes of collaborative problem solving is characterized as a style of collaborative thinking of the group.

3. In accordance with the type of function that dominates among the others in their combination, the following styles of group thinking were identified: initiative style-the generation function dominates; critical style-the selection function dominates; management style - the meaning transfer function dominates; practical style - the implementation function dominates.

\section{Acknowledgments}

The authors are grateful to all participants of the research - students of Don State Technical University and Southern Federal University.

\section{Conflict of interests}

The author declares no conflict of interest.

\section{References}

Ahonen, A., \& Harding, S. M. (2018). Assessing online collaborative problem solving among school children in finland: a case study using ATC21S TM in a National Context. International Journal of Learning, Teaching and Educational Research, 17(2), 138-158. https://doi.org/10.26803/iliter.17.2.9

Bales, R. F. (1950). Interaction process analysis; a method for the study of small groups. Cambridge, Mass: Addison-Wesley. Retrieved from https://ia902609.us.archive.org/32/items/interactionproce00bale/interactionproce00bale.pdf

Belbin, R. M. (1993). Team Roles at Work (London: Butterworth-Heinemann). Retrieved from https://www.belbin.com/resources/ belbin-papers-and-reports/ 
Belousova, A. (2020). Functions of participants in the collaborative solution of thinking problems, International Journal of Cognitive Research in Science, Engineering and Education (IJCRSEE), (8), Special issue of Current Research and Trends in Cognitive Sciences 2020, 29-36.

Belousova A. K. (2002). Самоорганизация совместной мыслительной деятельности [Collaborative Thinking Activity Self-Organization]. Ростов-на-Дону: РГПУ. Retrieved from https://www.elibrary.ru/item.asp?id=23550556

Belousova A. K. (2010). Initiation of Collaborative Thinking Activity Self-Organization: Basic conceptions and experimental research of collaborative thinking activity generation. Saarbrücken: LAP LAMBERT. Retrieved from https://www. morebooks.de/store/gb/book/initiation-of-collaborative-thinking-activity-self-organization/isbn/978-3-8433-7190-2

Belousova A. K. (2013). Editorial. International Journal of Cognitive Research in Science, Engineering and Education (IJCRSEE), 2(1), Retrieved from https://www.ijcrsee.com/index.php/ijcrsee/issue/view/1/1

Burch, G. F., Burch, J. J., \& Batchelor, J. H. (2019). Group Creative Problem Solving: The Role of Creative Personality, Process and Creative Ability. Quality Innovation Prosperity, 23(3), 38-54. https://doi.org/10.12776/QIP.V23I3.1286

Calvo, P., \& Gomila, T. (Eds.). (2008). Handbook of cognitive science: An embodied approach. Elsevier. https://doi.org/10.1016/ B978-0-08-046616-3.X0001-1

Care, E., Scoular, C., \& Griffin, P. (2016). Assessment of collaborative problem solving in education environments. Applied Measurement in Education, 29(4), 250-264. https://doi.org/10.1080/08957347.2016.1209204

Chen, L., Yoshimatsu, N., Goda, Y., Okubo, F., Taniguchi, Y., Oi, M., ... \& Yamada, M. (2019). Direction of collaborative problem solving-based STEM learning by learning analytics approach. Research and Practice in Technology Enhanced Learning, 14(1), 1-28. https://doi.org/10.1186/s41039-019-0119-y

Craig G. J., \& Baucum, D. (2001). Human Development. New Jersey: Prentice Hall. Retrieved from https://books.google.ru/ books/about/Human_Development.html?id=a9B9AAAAMAAJ\&redir_esc=y

Dautov, D. F. (2009). Influence of creative abilities on group's functional and role structure. Russian psychological journal, 6(1), 84-86. https://doi.org/10.21702/rpj.2009.1.13

Gellert M, \& Nowak C. (2000). A practical book for working in and with teams. Limmer Verlag, Retrieved from http://www. trainertreffen.de/tkb-news/literatur/050907\%20limmer\%20verlag.htm

Gadzhiev, СН.М. (1983). Организация коллективного изобретательства. В книге: Исследование проблем психологии творчества [Organization of collective invention. In the book: Research into the problems of the psychology of creativity]. Москва: Наука, 1983. С.266-279. Moscow: Nauka, pp. 266-279.

Griffin P. (2017) Assessing and Teaching 21st Century Skills: Collaborative Problem Solving as a Case Study. In: von Davier A., Zhu M., Kyllonen P. (eds) Innovative Assessment of Collaboration. Methodology of Educational Measurement and Assessment. Springer, Cham. https://doi.org/10.1007/978-3-319-33261-1_8

Griffin P., Care E., \& Harding SM. (2015) Task Characteristics and Calibration. In: Griffin P., Care E. (eds) Assessment and Teaching of $21^{\text {st }}$ Century Skills. Educational Assessment in an Information Age. Springer, Dordrecht. https://doi. org/10.1007/978-94-017-9395-7_7

Griffin, P., \& Care, E. (Eds.). (2014). Assessment and teaching of $21^{\text {st }}$ century skills: Methods and approach. Springer. https:/l doi.org/10.1007/978-94-017-9395-7

Griffin, P., Care, E., \& McGaw, B. (2012). The changing role of education and schools. In Assessment and teaching of $21^{\text {st }}$ century skills (pp. 1-15). Springer, Dordrecht. https://doi.org/10.1007/978-94-007-2324-5_1

Harding, S. M. E., Griffin, P. E., Awwal, N., Alom, B. M., \& Scoular, C. (2017). Measuring collaborative problem solving using mathematics-based tasks. AERA Open, 3(3), 1-19. 2332858417728046. https://doi.org/10.1177/2332858417728046

Harding, S. M., \& Griffin, P. E. (2016). Rasch Measurement of Collaborative Problem Solving in an Online Environment. Journal of Applied Measurement, 17(1), 35-53. Retrieved from https://pubmed.ncbi.nlm.nih.gov/26784377/

Hesse F., Care E., Buder J., Sassenberg K., Griffin P. (2015) A Framework for Teachable Collaborative Problem Solving Skills. In: Griffin P., Care E. (eds) Assessment and Teaching of 21st Century Skills. Educational Assessment in an Information Age. Springer, Dordrecht. https://doi.org/10.1007/978-94-017-9395-7_2

Lioe, L. T., Fai, H. K., \& Hedberg, J. G. (2006). Students' Metacognitive Problem-Solving Strategies in Solving Openended Problems in Pairs. In Redesigning Pedagogy (pp. 243-259). Brill Sense. https://doi.org/10.1163/9789087900977_018

Lipponen, L. (2002, January). Exploring foundations for computer-supported collaborative learning. In CSCL (Vol. 2, pp. 7281). https://doi.org/10.3115/1658616.1658627

Pavlova, T. V. (2015). Распределение функций в совместной мыслительной деятельности дошкольников с разным типом личности [Distribution of functions in the joint mental activity of preschoolers with different personality types]. Вестник Саратовского областного института развития образования, 4(4), 26-35. Retrieved from https:// www.elibrary.ru/author_items.asp?authorid=222894\&pubrole=100\&show_refs=1\&show_option=0

Rudestam, K. E. (1982). Experiential groups in theory and practice. Brooks/Cole Pub Co.

Schindler, R. (1968). Dynamische Prozesse in der Gruppenpsychotherapie [Dynamic processes in group psychotherapy]. Z Gruppenpsychother Gruppendyn, 1, 31-37.

Szary, J., \& Dale, R. (2013). Dyadic cooperation enhances retrieval and recall of crossword solutions. In Proceedings of the Annual Meeting of the Cognitive Science Society, 35(35). Retrieved from https://escholarship.org/uc/item/5ck4z7p6

Tikhomirov, О. К. (2008). Психология мышления [The psychology of thinking]. Moscow: Academy. Retrieved from https:// elibrary.ru/author items.asp?authorid $=71844 \&$ show refs $=1 \&$ show option $=1$

Uznadze D. N. (2001). Психология установки [The Psychology of Set]. Санкт-Петербург: Питер. Retrieved from https:// royallib.com/book/uznadze_dmitriy/psihologiya_ustanovki.html

Vygotsky L. S. (1983). Проблемы развития психики [Problems of the development of the psyche]. V.3. [In Collected works: In the 6 volumes]. Moscow: Pedagogy, Retrieved from http://elib.gnpbu.ru/text/vygotsky_ss-v-6tt_t3_1983/go,2;fs,1/

Vygotsky L. S. (1986). Конкретная психология человека. Вестн. Моск. ун-ma. Сеp, 14, 52-65. Retrieved from https://bookap. info/genpsy/vygotskiy_stati_konspekty_materialy_iz_lichnogo_arhiva_ls_vygotskogo/load/pdf.shtm

Vygotsky L. S. (2005). Психология развития человека [Human developmental psychology]. - Moscow: Smysl; Eksmo. Retrieved from http://lchc.ucsd.edu/mca/Mail/xmcamail.2008_07.dir/att-0052/problema_razvitiya_i_raspada_vysshih_ psih funkciy.pdf

Yaroshevsky M. G., Yurevich A. V., \& Allakhverdyan A. G. (2000). Программно-ролевой подход и современная наука [Rolebased approach and modern science. Psychology issues]. Вопросы психологии, (6), 3-18. Retrieved from https:// elibrary.ru/item.asp?id=20207733

Yuan, J., Xiao, Y., \& Liu, H. (2019). Assessment of Collaborative Problem Solving Based on Process Stream Data: A New 
Belousova, A. (2020). Functions of participants in the collaborative solution of thinking problems, International Journal of Cognitive Research in Science, Engineering and Education (IJCRSEE), (8), Special issue of Current Research and Trends in Cognitive Sciences 2020, 29-36.

Paradigm for Extracting Indicators and Modeling Dyad Data. Frontiers in Psychology, 10, 369. https://doi.org/10.3389/ fpsyg.2019.00369 